\title{
-759C > T Polymorphism of the HTR2C Gene is Associated with Second Generation Antipsychotic- Induced Weight Gain in Female Patients with Schizophrenia
}

Authors

Affiliations
F. M. Daray ${ }^{1,2}$, D. Rodante ${ }^{1,3}$, L. G. Carosella ${ }^{3}$, M. E. Silva ${ }^{3}$, M. Martínez ${ }^{4}$, M. V. Fernández Busch ${ }^{4}$, D. F. Faccone $^{2,4}$, R. P. Rothlin 1 , P. C. Maffía ${ }^{2,4}$

Affiliation addresses are listed at the end of the article

\author{
Key words \\ - second generation \\ antipsychotic \\ weight gain \\ - HTR2C gene \\ schizophrenia
}

\section{Abstract}

$\nabla$

Introduction: The HTR2C gene is an important candidate in pharmacogenetic studies of antipsychotic-induced weight gain (AIWG). However, inconsistent results have been obtained. The present study investigated the association between $-759 \mathrm{C}>\mathrm{T}$, functional polymorphism of the HTR2C receptor, and AIWG.

Methods: A prospective cohort of 48 female inpatients with schizophrenia and related illness treated according to normal clinical practice with second generation antipsychotics (SGAs) risperidone, clozapine, quetiapine, and olanzapine were evaluated. Patients were weighted at admission

\section{Introduction}

\section{$\nabla$}

Second generation antipsychotics (SGAs) are first-line drugs used for the treatment of patients suffering from schizophrenia and related psychotic disorders; however, these medications induce weight gain in up to $30 \%$ of patients [1]. Antipsychotic-induced weight gain (AIWG) can lead to obesity and metabolic syndrome, as well as social stigmatization, decreased quality of life, and noncompliance; therefore, these serious adverse effects warrant further attention in clinical practice $[2,3]$.

AIWG may be observed in the first few weeks of treatment and, in many cases, will continue up to a year following treatment. Both the incidence and the magnitude of weight gain is influenced by the type of drug being maximal with clozapine and olanzapine, minimal with ziprasidone and aripiprazole, and intermediate with risperidone and quetiapine [4].

Although the mechanism by which these drugs produce weight gain has not been fully elucidated, the serotoninergic system has emerged as a strong candidate $[5,6]$. The $5-\mathrm{HT}_{2 \mathrm{C}}$ receptor (encoded by the HTR2C gene) mediates, at least in and again at 6 weeks of hospitalization. Weight gain was defined as an increase $\geq 7 \%$ of baseline weight. The association between polymorphisms HTR2C and weight gain was evaluated. Multiple logistic regression was run to determine potential confounders.

Results: Patients with the $\mathrm{T}$ allele at position -759 (TT or CT) gained less weight as compared to patients who did not have the allele. This association was not affected by possible confounding factors such as age, baseline BMI, and prior psychopharmacological treatment.

Discussion: The $\mathrm{T}$ allele at position -759 protects against AIWG in female patients with schizophrenia. part, the metabolic side effects of SGAs. This observation is supported by data obtained among mice "knocked out" for this receptor in which hyperphagia, obesity, and hyperinsulinemia were observed [7]; second, the 2 SGA that induced greater weight gain (clozapine and olanzapine) evidence high affinity for the $5-\mathrm{HT}_{2} \mathrm{C}$ receptor [6].

Interracial and inter-individual variability in AIWG and the results observed in twin and adoption studies suggest that certain genetic factors may be relevant in this regard [8-10]. Evidence suggests that the HTR2C gene contains a polymorphic variant in the promoter region, $-759 \mathrm{C}>\mathrm{T}$ (rs3813929), which evidences functional consequences related to its ability to bind transcription factors and modify the expression of gene product $[11,12]$. Increased activity of the $5-\mathrm{HT}_{2 \mathrm{C}}$ receptor resulting from genetic variations in the HTR2C may increase circulating leptin levels resulting in greater weight gain, while variants that decrease expression of the receptor may be protective of weight gain induced by SGA [13]. One of these polymorphisms, $-759 \mathrm{C}>\mathrm{T}$, has been targeted in several association studies focused on the association between antipsychotic medica- 
tion and weight gain among patients diagnosed with schizophrenia, evidencing conflicting results. Some of these studies have found that individuals with the T allele of the HTR2C have less weight gain during treatment with SGAs [14-22]; others have failed to reproduce this result [23-26], while others found the opposite result [27]. There are several possible causes for this discrepancy, such as previous antipsychotic treatment, patient's ethnicity, and duration of SGA trial. It is noteworthy that in addition to the $-759 \mathrm{C}>\mathrm{T}$ polymorphism of the HTR2C gene other polymorphisms have been involved in genetic studies related to metabolic disturbances and antipsychotics [2830].

The aim of the present study was to examine the possible association between the $-759 \mathrm{C}>\mathrm{T}$ polymorphism of the HTR2C gene and AIWG among female patients diagnosed with schizophrenia. It was hypothesized that the variant -759T alleles would evidence a protective effect against AIWG.

\section{Methods \\ $\nabla$ \\ Study design}

A prospective cohort of inpatients treated according to normal clinical practice with SGAs was evaluated to assess the possible association between a HTR2C receptor polymorphism and AIWG.

\section{Participants}

The sample consisted of 48 Caucasian women diagnosed with schizophrenia or related illness and admitted at the Emergency Service of the "Dr. Braulio A. Moyano" Neuropsychiatric Women Hospital in Buenos Aires City, Argentina.

\section{Measures and assessment}

The present study was approved by the Ethics Committee of the Institution. Following hospital admission, all potential patients were given a complete description of the study and invited to participate. All participants and their legal representatives gave informed written consent for participation.

Inclusion criteria included meeting the Diagnostic and Statistical Manual-Fourth Edition Text Revision (DSM-IV-TR) criteria for schizophrenia, brief psychotic disorder, schizophreniform disorder, or delusional disorder and receiving treatment with SGA having high (olanzapine and clozapine) or moderate (risperidone and quetiapine) risk to induce weight gain.

Exclusion criteria included 1 month of treatment with SGAs or psychoactive medications that can produce weight changes (i.e., mood stabilizers and antidepressants) prior to admission; alcohol abuse or substance use 1 month prior to admission; use during the current hospitalization of other psychotropic or non-psychotropic drug that induced weight gain or glycemic dysregulation (only benzodiazepines and anticholinergics were allowed); presence of medical conditions that could modify the weight (i.e., diabetes, hyperthyroidism, etc.); and diagnosis of psychiatric conditions that may influence weight (i.e., eating disorders, etc.).

Patients included in the study received risperidone (mean dose $[S D]=5.03 \mathrm{mg} / \mathrm{day} \pm 1.77 \mathrm{mg} / \mathrm{day} ; \mathrm{n}=40$ ), olanzapine (mean dose $[S D]=14.20 \mathrm{mg} /$ day $\pm 3.76 \mathrm{mg} /$ day; $\mathrm{n}=6$ ), clozapine $($ dose $=400 \mathrm{mg} /$ day; $n=1$ ), and quetiapine (dose=150 mg/day; $n=1$ ).

Each patient underwent a structured clinical evaluation leading to a diagnosis based on DSM-IV-TR criteria for schizophrenia, brief psychotic disorder, schizophreniform disorder, or delu- sional disorder. Also, a list of questions regarding demographic and clinical variables was obtained. At admission, (baseline) weight, height, and calculation of body mass index (BMI, defined as weight $[\mathrm{kg}] /$ height $\left.^{2}\left[\mathrm{~m}^{2}\right]\right)$, using standardized procedures, were obtained. During the study period, all patients received the same dietetically balanced hospital meals. At the sixth week of treatment (trial's end), measurement of weight and BMI calculation were obtained.

At the last measurement, the researcher obtained a sample of the patients' peripheral blood, via the index finger prick with a lancet, to determine the HTR2C polymorphism. The peripheral blood drops were placed on Whatman FTA Classic Cards (Cat. no. WB120205; Whatman International Ltd, Piscataway, NJ, USA). Patients then continued treatment according to the physician's clinical judgment. Samples were transported to the Laboratory of Molecular Microbiology, National University of Quilmes, Argentina, where the genetic analysis was performed.

\section{Genetic analysis}

Following the 6-week period, all genotyping procedures were conducted by a researcher who was unaware of the clinical status of the patients.

We amplified a 252 bp fragment of the HTR2C gene regulatory region from genomic DNA by polymerase chain reaction (PCR), as described by others [31].

The polymorphism analysis of the PCR product was performed by DNA sequencing using the BigDye terminator methodology with an ABI 3130xl Genetic Analyzer (Applied Biosystems/PerkinElmer, Foster City, CA, USA). Nucleotide sequence editing and analyses were performed using BioEdit v7.0.9 (http://www. mbio.ncsu.edu/bioedit/bioedit.html) and ClustalX2 v2.1 (http:// www.clustal.org/clustal2/).

\section{Statistical analysis}

Categorical measures were reported as frequency or percentage and compared by use of contingency tables $\left(\mathrm{X}^{2}\right)$. Continuous measures were reported as means \pm standard deviation (SD) and compared by ANOVA methods ( $t$-test) or Wilcoxon rank-sum test (Mann-Whitney $U$-statistic) for non-normally distributed continuous data.

Given the hypotheses were that the variant -759T allele would have a protective effect against AIWG, the CT heterozygous and TT homozygous (for $-759 \mathrm{C}>\mathrm{T}$ ) were combined for the analysis. To make our results comparable with other studies we classified patients as weight gainers ( $\geq 7 \%$ of baseline weight) and nonweight gainers ( $<7 \%$ of baseline weight).

Multiple logistic regression modeling was used to evaluate factors significantly associated with AIWG. Specifically, the independent variables age, prior psychopharmacological treatment, and baseline BMI were included at stepwise. Adjusted slope $(\beta)$ coefficients and their $95 \% \mathrm{CI}$ from logistic regression modeling were reported, with significance evaluated using Wald tests. Statistical significance was set at 2-tailed $\mathrm{p}<0.05$. Analyses were done via STATA.12 (StataCorp, College Station, TX, USA) commercial statistical software.

\section{Results \\ $\nabla$}

The current study included a total of 48 inpatient women treated with SGAs. The average age of the female sample was 34.48 years $(S D=13.13)$, and almost 2-thirds reported no previous psy- 
Table 1 Clinical and demographic characteristics of the patients included in the study $(n=48)$.

\begin{tabular}{|c|c|c|c|c|}
\hline & \multirow[t]{2}{*}{ Total sample } & \multicolumn{2}{|c|}{$-759 C>T$ polymorphism of the HTR2C gene } & \multirow[t]{2}{*}{ p-value } \\
\hline & & $\begin{array}{l}\text { Genotypes with presence } \\
\text { of the T allele ( } n=11,23 \%)\end{array}$ & $\begin{array}{l}\text { Genotypes without the pres- } \\
\text { ence of the T allele ( } n=37,77 \% \text { ) }\end{array}$ & \\
\hline Age, mean (SD) & $34.48(13.13)$ & $36.73(15.17)$ & $33.81(12.62)$ & 0.52 \\
\hline Education (years), mean (SD) & $11.34(3.46)$ & $11.54(3.11)$ & $11.28(3.61)$ & 0.83 \\
\hline Caucasian, n (\%) & $47(98)$ & $11(100)$ & $36(97)$ & 0.581 \\
\hline \multicolumn{5}{|l|}{ Diagnosis, n (\%) } \\
\hline Paranoid & $23(48)$ & $7(64)$ & $16(43)$ & \\
\hline Hebephrenic & $10(21)$ & $2(18)$ & $8(22)$ & \\
\hline Other & $15(31)$ & $2(18)$ & $13(35)$ & \\
\hline Family history of psychiatric illness, n (\%) & $31(66)$ & $9(82)$ & $22(59)$ & 0.43 \\
\hline $\begin{array}{l}\text { Patients without prior psychopharmacological } \\
\text { treatment, n (\%) }\end{array}$ & $29(60)$ & $7(64)$ & $22(59)$ & 0.80 \\
\hline Smoking, n (\%) & $20(42)$ & $3(27)$ & $17(46)$ & 0.24 \\
\hline Weight (kg) at trial entry, mean (SD) & $64.29(13.95)$ & $60.50(12.78)$ & $65.42(14.25)$ & 0.31 \\
\hline Weight (kg) after 6 weeks, mean (SD) & $66.52(13.94)$ & $60.92(12.15)$ & $68.18(14.16)$ & 0.06 \\
\hline Height $\left(\mathrm{m}^{2}\right)$, mean (SD) & $1.61(0.08)$ & $1.59(0.08)$ & $1.62(0.07)$ & 0.19 \\
\hline Body Mass Index $\left(\mathrm{kg} / \mathrm{m}^{2}\right)$ at trial entry, mean (SD) & $24.61(5.12)$ & $23.94(4.97)$ & $24.83(5.22)$ & 0.62 \\
\hline Patients with weight gain ${ }^{*}, \mathrm{n}(\%)$ & 18 & $1(9)$ & $17(46)$ & 0.03 \\
\hline
\end{tabular}

$\mathrm{SD}=$ standard deviation, ${ }^{*}$ Weight gain was defined as an increase $\geq 7 \%$ of baseline weight

Table 2 Factors associated with weight gain during SGA treatment: multivariate logistic model.

\begin{tabular}{llll} 
Factor & Adjusted OR [95\% Cl] & $\mathbf{X}^{2}$ & p-value \\
\hline Age (years) & $0.98[0.92-1.04]$ & -0.65 & 0.52 \\
\hline Baseline BMI $\left(\mathrm{kg} / \mathrm{m}^{2}\right)$ & $0.97[0.84-1.12]$ & -0.39 & 0.70 \\
Prior psychopharmacological & $0.33[0.07-1.42]$ & -1.49 & 0.14 \\
treatment (yes/no) & & \\
\multicolumn{2}{l}{ OR=odds ratio; $\mathrm{Cl}=$ confidence interval, BMI=Body Mass Index $\left(\mathrm{kg} / \mathrm{m}^{2}\right)$}
\end{tabular}

chopharmacological treatment (60\%). The most frequent diagnoses were paranoid schizophrenia (48\%) and hebephrenic schizophrenia (21\%). Baseline data indicated an average weight of $64.29 \mathrm{~kg}$, height of $1.61 \mathrm{~m}$, and BMI of $24.61 \mathrm{~kg} / \mathrm{m}^{2} .18$ patients (38\%) increased $\geq 7 \%$ of baseline weight during treatment with SGAs. Additional clinical and demographic variables may be found in $\odot$ Table 1.

As the $5 \mathrm{HT}_{2 \mathrm{C}}$ gene is located on the $\mathrm{X}$ chromosome, women presented in both heterocygotic and a homozygotic forms. The distribution and frequency of the polymorphisms analyzed in the sample under study for the $-759 \mathrm{C}>\mathrm{T}$ were CC $37 / 48$ (77\%), TT $1 / 48$ (2\%), CT 10/48 (21\%). No significant differences were observed when comparing the baseline clinical and demographic data between patients with different genotypes ( $\bullet$ Table 1 ).

After 6 weeks of treatment with SGAs, the average weight gain was $2.23 \pm 0.40 \mathrm{~kg}$. Those patients with the $-759 \mathrm{~T}$ allele gained less weight as compared to patients who did not have the allele $(0.43 \pm 0.50 \mathrm{~kg}, \mathrm{n}=11$ vs. $2.77 \pm 0.47 \mathrm{~kg}, \mathrm{n}=37 ; \mathrm{p}=0.006)$. Contingency table was used for the analysis of association between the genotypes containing HTR2C polymorphism and weight gain as a dichotomous variable. The table was built on the basis of the presence or absence of the variant allele thought to be protective against weight gain (-759T). Results suggest patients with the -759T allele in their genotype gained significantly less weight as compared to patients who did not have the allele $\left(X^{2}=4.91\right.$, $\mathrm{p}=0.03$,).

Because the relationship between polymorphism and weight gain can be influenced by certain factors such as age, baseline BMI, and the presence of previous drug treatments, a multiple logistic regression model was used to analyze each of these possible effects. There were no significant effects of these factors within the relation between genetic polymorphisms and AIWG (॰ Table 2).

\section{Discussion \\ $\nabla$}

The present study provides further evidence of the protective role of the $-759 \mathrm{~T}$ variant allele of the $-759 \mathrm{C}>\mathrm{T}$ polymorphism (rs3813929) of the HTR2C against AIWG in female patients with schizophrenia.

Weight gain is a common and important side effect associated with the use of SGAs; however, mechanisms underlying this side effect are not fully understood [32]. Serotonin is thought to play a key role in regulation of feeding behavior and satiety signaling. Indeed, serotonin receptors are considered an important candidate gene in pharmacogenetic studies of AIWG. The 5- $\mathrm{HT}_{2 \mathrm{C}}$ receptor, encoded by the $H T R 2 C$ gene, mediates at least in part the metabolic side effects of SGAs and is considered one of the most promising targets [33].

The gene encoded in the $5-\mathrm{HT}_{2 \mathrm{C}}$ receptor is located in chromosome Xq24 and presents numerous polymorphisms. One of these polymorphisms $(-759 \mathrm{C}>\mathrm{T})$ located in the promoter region is known to regulate gene expression $[11,30]$. The modifications in the expression of the $5-\mathrm{HT}_{2 \mathrm{C}}$ receptor, resulting from genetic variation in HTR2C, may increase the levels of circulating leptin, resulting in greater weight gain. Variants that decrease expression of the receptor may be protective of weight gain induced by SGAs $[13,34]$.

This polymorphism has been targeted in association studies between treatment with SGAs and weight gain, resulting in variable results. Yuan et al. (2000) were the first to report that the frequency of the variant -759T was greater in non-obese individuals, suggesting that the $\mathrm{T}$ allele operates as a protector of obesity in non-schizophrenic patients [31]. After that, Reynolds (2002) suggested a protective effect of the variant -759T allele against antipsychotic-induced weight gain in Chinese Han first episode schizophrenia patients receiving risperidone and chlorpromazine [35]. The subsequent pharmacogenetic studies that 
investigated this polymorphism reported inconsistent results. Some of them replicated these results analyzing patients treated with clozapine, olanzapine, or risperidone [14,17-22]. The current study supports the protective role of the -759T allele against AIWG in schizophrenic patients and provides more knowledge of this effect in female gender. Others studies have not found a positive association between this polymorphism and AIWG $[23,24,26,27,36]$.

Many factors may explain these differences, such as previous antipsychotic treatment, patient's ethnicity, and duration of SGA trial. Previous antipsychotic treatment seems to be the strongest factor that accounts for these discrepancies. Importantly, most of the studies with negative findings were performed with patients undergoing previous antipsychotic treatment [23-27]. Correspondingly, a meta-analysis [37], recently re-analyzed [38], demonstrated the overall risk of weight gain in patients without the $\mathrm{T}$ allele polymorphism was 2.7 times more likely than those with $\mathrm{T}$ allele, but when stratifying these results, an OR of 1.6 was observed in chronic schizophrenic patients in comparison with an OR of 5.4 in first episode patients. Altogether, this information means that the effect size of the association could be larger in first episode patients. The current study sample consisted of patients most of whom had no previous treatments, which may have influenced the positive association found. Furthermore, ethnicity may also account for these differences. For example, most of the previous studies included samples of European-American patients, where a significant association was detected; however, these findings were not replicated among some Asians populations (Korea and Japan). The current study included Caucasian patients mostly of European descent, which may account for the positive finding. Finally, duration of the treatment may also play a role in the positive association observed. Tempelman et al. (2005) investigated the association between the -759T allele and body weight gain in a Caucasian Spanish patient sample characterized by a first episode of psychosis at 6 weeks, 3 months, and 9 months, detecting that the most prominent association was found for short-term weight increases ( 6 weeks) [14]. The short duration (6 weeks) of treatment yielded by the current inpatient study design may also account for the positive findings of the impact of the -759T polymorphism on AIWG.

Since the HTR2C gene is located on the X chromosome, the association of the -759T allele with AIWG has been thought to be dependent on sex. For example, Reynolds et al. (2003) found that the association was strongest in male patients and not apparent in female patients, suggesting that the protective effect of the allele was dependent on gender; however, their sample included only 11 women, which does not allow for definitive conclusions about this issue [16]. The majority of these studies published were performed in mixed samples with a low number of women, indicating an underpowered sample to detect sex differences. This was confirmed by Kuzman et al. (2008), who performed an association study with a female sample and concluded that the $-759 C>$ T polymorphism of the HTR2C gene does not play a significant role in susceptibility to weight gain in women [36]. Our results differ from those of Kuzman et al. probably given the differences between the durations of the studies ( 4 months in theirs vs. 6 weeks in ours).

There are several potential confounders found in the relation between the -759T allele and AIWG, such as age, initial BMI, and previous antipsychotic treatment. In the present study, we used the logistic regression in order to establish the role of these fac- tors. Based on the results of the regression, we can conclude that the protective effect on weight gain conferred by the T allele was independent of these factors.

The present study has relevance for the development of predictive tests to help clinicians to identify which patients are more susceptible to AIWG.

\section{Limitations}

The present study has some limitations that should be considered. First, based on the experimental design, there are some variables related to weight gain that were unable to be controlled for, such as diet and physical activity. However, only inpatients were enrolled in the study; all followed the same diet plan during hospitalization with no free access to food or snacks. Physical activity was also comparable for all patients throughout the study period. Second, the study sample was small; yet, the "Braulio A. Moyano" Hospital is only for women, which allowed us to obtain a female homogenize sample. Given that gender differences are important in AIWG, the results add to the topic. Finally, the design of the study is observational (prospective cohort), and therefore, neither the type nor the dose of SGA was defined experimentally. The modest number of patients with different types of SGAs limited the statistical power to analyze the association for different antipsychotics; however, all SGAs employed are considered to induce weight gain and the doses are within the usual range of doses employed in the clinical practice. Taken together, the results reproduce the same conditions as in a clinical setting.

\section{Funding}

$\nabla$

Supported in part by the Foundation "Alberto J. Roemmers" and the Argentine National Scientific and Technical Research Council (CONICET, Resolución N4541-12 y Resolución N³646/14).

\section{Conflict of Interest}

$\nabla$

No author or immediate family member has financial relationships with commercial entities that might appear to represent a potential for conflicts of interest.

Affiliations

${ }^{1}$ Instituto de Farmacología, Facultad de Medicina, Universidad de Buenos Aires. Argentina. Paraguay 2155, piso 9, Ciudad Autónoma de Buenos Aires, Argentina

${ }^{2}$ Consejo Nacional de Investigaciones Científicas y Técnicas (CONICET), Buenos Aires, Argentina

Servicio de Emergencia, Hospital "Braulio A. Moyano”, Buenos Aires, Argentina

${ }^{4}$ Laboratorio de Microbiología Molecular, Universidad Nacional de Quilmes, Argentina

\section{References}

1 Lieberman JA, Stroup TS, McEvoy JP et al. Effectiveness of antipsychotic drugs in patients with chronic schizophrenia. N Engl J Med 2005; 353: $1209-1223$

2 Perkins DO. Predictors of noncompliance in patients with schizophrenia. J Clin Psychiatry 2002; 63: 1121-1128

3 Weiden PJ, Mackell JA, McDonnell DD. Obesity as a risk factor for antipsychotic noncompliance. Schizophr Res 2004; 66: 51-57

4 Shams TA, Muller DJ. Antipsychotic induced weight gain: genetics, epigenetics, and biomarkers reviewed. Curr Psychiatry Rep 2014; 16: 473

5 Daray FM, Maffia PC, Rothlin RP et al. Pharmacogenetics in psychiatry: how far are we from clinical application? Vertex 2012; 23: 299-309 
6 Stahl SM, Mignon L, Meyer JM. Which comes first: atypical antipsychotic treatment or cardiometabolic risk? Acta Psychiatr Scand 2009; 119: 171-179

7 Tecott LH, Sun LM, Akana SF et al. Eating disorder and epilepsy in mice lacking 5-HT2c serotonin receptors. Nature 1995; 374: 542-546

8 Gebhardt S, Theisen FM, Haberhausen $M$ et al. Body weight gain induced by atypical antipsychotics: an extension of the monozygotic twin and sib pair study. J Clin Pharm Ther 2010; 35: 207-211

9 Wehmeier PM, Gebhardt S, Schmidtke J et al. Clozapine: weight gain in a pair of monozygotic twins concordant for schizophrenia and mild mental retardation. Psychiatry Res 2005; 133: 273-276

10 Theisen FM, Cichon S, Linden A et al. Clozapine and weight gain. Am J Psychiatry 2001; $158: 816$

11 Hill MJ, Reynolds GP. Functional consequences of two HTR2C polymorphisms associated with antipsychotic-induced weight gain. Pharmacogenomics 2011; 12: 727-734

12 Hill MJ, Reynolds GP. 5-HT2C receptor gene polymorphisms associated with antipsychotic drug action alter promoter activity. Brain Res 2007; 1149: 14-17

13 Reynolds GP, Hill MJ, Kirk SL. The 5-HT2C receptor and antipsychoticinduced weight gain - mechanisms and genetics. J Psychopharmacol 2006; 20: 15-18

14 Templeman LA, Reynolds GP, Arranz B et al. Polymorphisms of the 5-HT2C receptor and leptin genes are associated with antipsychotic drug-induced weight gain in Caucasian subjects with a first-episode psychosis. Pharmacogenet Genomics 2005; 15: 195-200

15 Reynolds GP. Weight gain, antipsychotic drug treatment and pharmacogenomics. Pharmacogenomics 2002; 3: 567-570

16 Reynolds GP, Zhang Z, Zhang X. Polymorphism of the promoter region of the serotonin 5-HT(2C) receptor gene and clozapine-induced weight gain. Am J Psychiatry 2003; 160: 677-679

17 Miller DD, Ellingrod VL, Holman TL et al. Clozapine-induced weight gain associated with the $5 \mathrm{HT} 2 \mathrm{C}$ receptor $-759 \mathrm{C} / \mathrm{T}$ polymorphism. Am J Med Genet B Neuropsychiatr Genet 2005; 133B: 97-100

18 Ryu S, Cho EY, Park T et al. -759 C/T polymorphism of 5-HT2C receptor gene and early phase weight gain associated with antipsychotic drug treatment. Prog Neuropsychopharmacol Biol Psychiatry 2007; 31: 673-677

19 Opgen-Rhein C, Brandl EJ, Muller DJ et al. Association of HTR2C, but not LEP or INSIG2, genes with antipsychotic-induced weight gain in a German sample. Pharmacogenomics 2010; 11: 773-780

20 Ellingrod VL, Perry PJ, Ringold JC et al. Weight gain associated with the $-759 \mathrm{C} / \mathrm{T}$ polymorphism of the 5HT2C receptor and olanzapine. Am J Med Genet B Neuropsychiatr Genet 2005; 134B: 76-78

21 Godlewska BR, Olajossy-Hilkesberger L, Ciwoniuk $M$ et al. Olanzapineinduced weight gain is associated with the $-759 \mathrm{C} / \mathrm{T}$ and $-697 \mathrm{G} / \mathrm{C}$ polymorphisms of the HTR2C gene. Pharmacogenomics J 2009; 9: 234-241

22 Lane HY, Liu YC, Huang CL et al. Risperidone-related weight gain: genetic and nongenetic predictors. J Clin Psychopharmacol 2006; 26: $128-134$
23 Tsai SJ, Hong CJ, Yu YW et al. -759C/T genetic variation of 5HT(2C) receptor and clozapine-induced weight gain. Lancet 2002; 360: 1790

24 Theisen FM, Hinney A, Bromel T et al. Lack of association between the $-759 \mathrm{C} / \mathrm{T}$ polymorphism of the 5-HT2C receptor gene and clozapineinduced weight gain among German schizophrenic individuals. Psychiatr Genet 2004; 14: 139-142

25 Park YM, Cho JH, Kang SG et al. Lack of association between the -759C/T polymorphism of the 5-HT2C receptor gene and olanzapine-induced weight gain among Korean schizophrenic patients. J Clin Pharm Ther 2008; 33: 55-60

26 Ujike H, Nomura A, Morita Y et al. Multiple genetic factors in olanzapine-induced weight gain in schizophrenia patients: a cohort study. J Clin Psychiatry 2008; 69: 1416-1422

27 Basile VS, Masellis M, De Luca V et al. 759C/T genetic variation of $5 \mathrm{HT}(2 \mathrm{C})$ receptor and clozapine-induced weight gain. Lancet 2002; 360: $1790-1791$

28 Mulder H, Franke B, Arends J et al. The association between HTR2C gene polymorphisms and the metabolic syndrome in patients with schizophrenia. Journal of clinical psychopharmacology 2007; 27: 338-343

29 Mulder H, Cohen D, Scheffer $H$ et al. HTR2C gene polymorphisms and the metabolic syndrome in patients with schizophrenia: a replication study. Journal of clinical psychopharmacology 2009; 29: 16-20

30 Reynolds GP, Templeman LA, Zhang ZJ. The role of 5-HT2C receptor polymorphisms in the pharmacogenetics of antipsychotic drug treatment. Prog Neuropsychopharmacol Biol Psychiatry 2005; 29: $1021-1028$

31 Yuan X, Yamada K, Ishiyama-Shigemoto $S$ et al. Identification of polymorphic loci in the promoter region of the serotonin 5-HT2C receptor gene and their association with obesity and type II diabetes. Diabetologia 2000; 43: 373-376

32 Correll CU, Lencz T, Malhotra AK. Antipsychotic drugs and obesity. Trends Mol Med 2011; 17: 97-107

33 Lett TA, Wallace TJ, Chowdhury NI et al. Pharmacogenetics of antipsychotic-induced weight gain: review and clinical implications. Mol Psychiatry 2012; 17: 242-266

34 Brennan MD. Pharmacogenetics of second-generation antipsychotics. Pharmacogenomics 2014; 15: 869-884

35 Reynolds GP, Zhang ZJ, Zhang XB. Association of antipsychotic druginduced weight gain with a 5 -HT2C receptor gene polymorphism. Lancet 2002; 359: 2086-2087

36 Kuzman MR, Medved V, Bozina $N$ et al. The influence of 5-HT(2C) and MDR1 genetic polymorphisms on antipsychotic-induced weight gain in female schizophrenic patients. Psychiatry Res 2008; 160: 308-315

37 Sicard MN, Zai CC, Tiwari AK et al. Polymorphisms of the HTR2C gene and antipsychotic-induced weight gain: an update and meta-analysis. Pharmacogenomics 2010; 11: 1561-1571

38 Zhang JP, Malhotra AK. Pharmacogenetics of antipsychotics: recent progress and methodological issues. Expert Opin Drug Metab Toxicol 2013; 9: 183-191 